\title{
NUTRIENT RECOVERY FROM ANAEROBICALLY DIGESTED ORGANIC WASTES
}

\author{
Deshai Botheju ${ }^{I}$ \\ Oystein Svalheim ${ }^{2}$ \\ Bjorn Rydtun ${ }^{2}$ \\ Jo-Ela Johansen ${ }^{2}$ \\ Rune Bakke \\ ${ }^{I}$ Telemark University College, Norway, \\ ${ }^{2}$ BioTek AS, Norway
}

\begin{abstract}
Effluents (digestates) resulting from anaerobic digestion of wet organic wastes can be recycled as fertilizers. Separation of such digestates into a wet and a dry fraction is common. The solid fraction is often sold as a soil enhancement product while the liquid fraction is usually discarded as wastewater. A large portion of the digestate nutrients is dissolved as ions in the liquid. The aim of this study is to establish an efficient way to convert this into a liquid "organic fertilizer". Enhancement of the nutrient concentration is necessary in order to make the final product commercially acceptable. Direct evaporative concentration is not suitable as it would lead to a significant loss of ammonia due to the fact that most of the available nitrogen in these digestates is present in the ammonium/ammonia form. Thus stabilizing the product by partial nitrification prior to evaporation is proposed based on a series of experiments conducted to evaluate the appropriateness of this approach.
\end{abstract}

The ammonium-N concentration of the digestate used was $1.7 \mathrm{~g} / \mathrm{L}$. The nitrification does not appear to be inhibited by ammonia, nitrate or nitrite accumulation, except when $\mathrm{pH}>7.5$, a situation that can be avoided by regulating the feeding rate based on $\mathrm{pH}$ measurements. Significant nitrite accumulation was not observed either. Nitrification is however consistently limited by alkalinity so that only about $75 \%$ of the ammonia can be converted to nitrate without alkalinity supplementation. The nitrification brings the $\mathrm{pH}$ down below 5.0 where the remaining ammonia is present as $>99 \% \mathrm{NH}_{4}{ }^{+}$. At this condition the nitrified digestate can be evaporated without a significant nitrogen loss and the product is recognized to be a high quality liquid fertilizer. It is suggested that the production of concentrated partially nitrified organic fertilizers can become a sustainable way of nutrient recovery from anaerobic digestates originating from municipal organic wastes.

\section{KEYWORDS}

Anaerobic digestion; Nutrient recovery; Organic fertilizer; Partial nitrification; Wet organic wastes. 


\section{INTRODUCTION}

Nutrient mismanagement can lead to disastrous environmental alterations due to excessive accumulation of Nitrogen in soil and water. Eutrification of surface water bodies, ammonia toxicity in aquatic life forms, groundwater poisoning, acid rains, assisting ground level ozone and smog are among the major environmental impacts of different nitrogenous compounds resulting from untreated nutrient releases to open environment [1,2]. After the EU directive of 91/271/EEC [3], European member states were guided to adopt more stringent water nutrient standards and incorporate nutrient removal stages into their wastewater treatment facilities. However, instead of following the traditional nitrogen removal treatment strategy which converts chemically bound nitrogen into $\mathrm{N}_{2}$ gas, the modern day treatment practice encourages the reuse and recycle of nutrients from wastes. For example, it is estimated that the recycling nutrients from domestic wastes can replace $35-45 \%$ of the (industrially produced and energy intensive) fertilizer use [1]. This level of nutrient recycling will be essential in future for achieving a sustainable relationship between the natural environment and ever increasing human interferences on it.

The effluents from anaerobic digesters operating on municipal organic wastes contain relatively high amounts of ammoniacal nitrogen. This is due to the reason that ammonium being one of the basic end products of protein metabolism [4] and municipal organic wastes are usually rich in protein sources instigating from food residues. On the other hand, methane fermentation processes do not fix nutrients in an effective manner [5,6]. In fact anaerobic digestion increases the content of soluble nutrients via dissolution of particulate organic matter [6] by hydrolysis and other degradation pathways. Not only the proteins but also various other organic nitrogenous compounds such as amino acids, urea, etc., are mainly reduced to ammonia under the anaerobic conditions, but ammonia itself cannot be further degraded without an aerobic treatment stage [2] to oxidize ammonical nitrogen to nitrites and nitrates.

The direct application of anaerobic digestates as nitrogen fertilizers in farmlands $[5,6]$ is the most straightforward method of nutrient recycling in small scale and closed systems (like small scale farms, diaries, sugar mills etc.). But when it comes to the large commercial scale applications, such easy dumping may not be acceptable due to number of reasons including, the state's guidelines on toxic substances in commercial fertilizers (e.g. heavy metals), the public acceptance based on aesthetic quality of the product (odor, color, particulate matter etc.). However the most critical barrier for using these digestates as direct commercial fertilizers is the instability of the ammonical nitrogen $\left(\mathrm{NH}_{4}-\mathrm{N}\right)$ at and above neutral pH levels typical for digestates. The high ammonical nitrogen content hinders the capability of concentrating these digestates by evaporation as it tends to release ammonia (gas), heavily reducing the fertilizer quality and causing air pollution.

Partial nitrification of such digestates prior to evaporative up-concentration is proposed to make a commercially acceptable high grade fertilizer product. Nitrification converts ammonical nitrogen into nitrates $\left(\mathrm{NO}_{3}^{-}\right)$which is more stable in the soil and is a highly mobile nitrogen source for plants. Nitrification can be achieved by biological means with two basic biochemical reactions. Ammonium is first oxidized into nitrite (Equation l) by a group of bacteria (nitritifiers) and then nitrite is further oxidized into nitrate (Equation 2) by another group of bacteria (nitratifiers). Both bacterial groups are aerobic autotrophic organisms. 
$2 \mathrm{NH}_{4}^{+}+3 \mathrm{O}_{2} \rightarrow 2 \mathrm{NO}_{2}^{-}+4 \mathrm{H}^{+}+2 \mathrm{H}_{2} \mathrm{O}$

$2 \mathrm{NO}_{2}^{-}+\mathrm{O}_{2} \rightarrow 2 \mathrm{NO}_{3}^{-}$

A laboratory study was carried out on nitrification of anaerobic digestates to investigate the feasibility of commercial grade liquid fertilizer production based on large scale municipal organic waste/food residue anaerobic digesters. The experiment was based on an assay of bioreactors comprising five intermittently fed continuously aerated nitrification columns.

\section{MATERIALS AND METHODS}

\subsection{Feed source}

The feed digestate was obtained from an active anaerobic digestion plant (Hadeland and Ringerike Avfallselskap, Jevnaker, Norway). This plant has a total reactor volume of $2300 \mathrm{~m}^{3}$ in three stage reactors; one hydrolysis tank $\left(350 \mathrm{~m}^{3}\right)$ followed by two consecutive methanogenic reactors (1500 and $450 \mathrm{~m}^{3}$ respectively). The plant is operated at a (total) hydraulic retention time of 20 days. This plant has been operating on municipal source separated organic residues for more than one year. The first methanogenic reactor is maintained at thermophilic conditions $\left(52-55^{\circ} \mathrm{C}\right)$ and the second digester is operated under ambient conditions without temperature control. At the time of the experiments reported here the effluent from this second reactor contained approximately $1700 \mathrm{mg} / \mathrm{L}$ of $\mathrm{NH}_{4}-\mathrm{N}$ (see Table 1), and was used as the feed source in this study.

Table 1. Characteristics of anaerobic digestate used.

\begin{tabular}{lll}
\hline Parameter & Value & Units \\
$\mathrm{NH}_{4}-\mathrm{N}$ & 1700 & $\mathrm{mg} / \mathrm{L}$ \\
$\mathrm{pH}$ & 8.05 & - \\
$\mathrm{COD}$ (soluble) & 3260 & $\mathrm{mg} / \mathrm{L}$ \\
Total solids & 23500 & $\mathrm{mg} / \mathrm{L}$ \\
Volatile solids & 15500 & $\mathrm{mg} / \mathrm{L}$ \\
Kjeldahl $-\mathrm{N}$ & 15.9 & $\mathrm{~g} / 100 \mathrm{~g} \mathrm{TS}$ \\
Total $\mathrm{P}$ & 233 & $\mathrm{mg} / \mathrm{L}$ \\
Total S & 95.2 & $\mathrm{mg} / \mathrm{L}$ \\
\hline
\end{tabular}

\subsection{Nitrification reactor set up}

The reactor assembly consisted of five glass columns ( $1 \mathrm{~m}$ height and $5 \mathrm{~cm}$ internal diameter) each equipped with aeration diffusers and tube connections (Tygon tubes of $6 \mathrm{~mm}$ outer diameter) to feed and take out samples. The diffusers placed at the bottom of the columns provided air supply and also the mixing. Continuous aeration was provided by aquarium aerators (Eheim 400, 4 Watts) with two channels in each unit.

The used inoculum was a mixture of, $4.0 \mathrm{~L}$ sludge from a nitrifying wastewater treatment facility (ESSO petroleum refinery at Slagentangen, Vestfold, Norway), $0.8 \mathrm{~L}$ sludge from a municipal wastewater treatment plant with biological $\mathrm{N}$ and $\mathrm{P}$ removal stages (Risor, Norway), and $0.2 \mathrm{~L}$ sludge from a bench top scale nitrification reactor operated on a synthetic 
nutrient feed $\left(4.438 \mathrm{~g} / \mathrm{L}\right.$ of $\left(\mathrm{NH}_{4}\right)_{2} \mathrm{SO}_{4}, 3.581 \mathrm{~g} / \mathrm{L}$ of $\mathrm{K}_{2} \mathrm{HPO}_{4}, 0.344 \mathrm{~g} / \mathrm{L}$ of $\mathrm{KH}_{\mathrm{Q}} \mathrm{PO}_{4}$, and $7.445 \mathrm{~g} / \mathrm{L}$ of $\mathrm{NaHCO}_{3}$ ). This inoculum mixture was pre-acclimated with the anaerobic digestate in an aerated vessel for 20 days before introduced to the reactor columns. During this period a total ofe $200 \mathrm{ml}$ of digestate was fed to the acclimatization vessel.

After starting the column assay experiment, each column was fed daily (for most of the experimental period) and the same amount of effluent was taken out before feeding. A sedimentation phase of 15 minutes was allowed (by stopping the aeration) before the effluent removal. Small amounts of tap water had to be added each day for the compensation of evaporation losses from the column tops. The effluents from all the reactors were collected and stored in a separate vessel in order to carry out other intended tests (e.g. evaporation tests, plant growth tests etc.), planned as a continuation of this study.

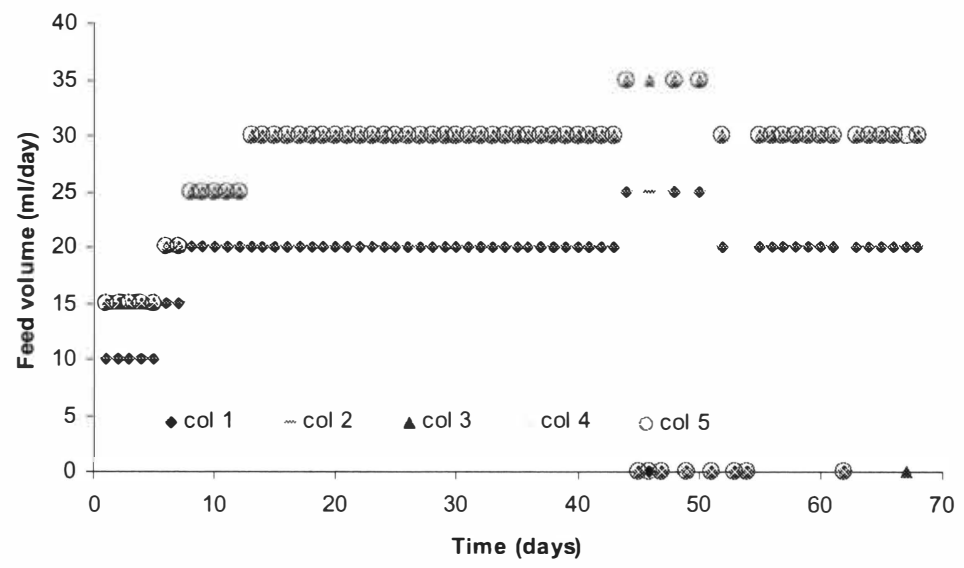

Figure 1. Volumetric feed pattern for the five columns.

\subsection{Operating conditions}

The reactors were operated in a laboratory ventilation hood maintained at $\sim 25{ }^{\circ} \mathrm{C}$ temperature. Two different $\mathrm{NH}_{4}-\mathrm{N}$ loading schemes were tested (Figure 1). In order to further acclimate the culture to the digestate feed and to avoid overloading, the columns were initially fed low amounts of daily feed volumes ( 10 and $15 \mathrm{~mL} /$ day) and then feeding volumes were stepwise increased. This step increasing was done from day 1 to day 12 until it reached the 20 and 30 $\mathrm{mL}$ /day steady feeding levels which were maintained constant during the main phase of the experimentation lasted for 31 days (from day 13 to day 43).

In addition to the difference in feed volumes, two of the columns (columns 1 and 5) were fed with the clear phase of gravity settled digestate (after allowing the digestate to sediment for one day in a $100 \mathrm{~mL}$ volumetric cylinder filled to a liquid height of $20 \mathrm{~cm}$ ). The other three columns (columns 2, 3 and 4), were fed with well mixed digestate. 
This unsedimented and sedimented feed difference was made to reveal possible effects on the process and the final product induced by the heavy particulate fraction of the digestate.

After finishing the main steady feeding phase of the experiment (31 days long), the increased volumes of 25 and $35 \mathrm{~mL} /$ day were fed during the period between day 44 and day 51 as displayed in Figure 1. Once again, during the period of day 52 to the end of the experiment (on day 68) feed volumes were reduced back to 20 and $30 \mathrm{ml} /$ day. The feeding was less regular during these last two periods.

\subsection{Analytical methods}

Daily $\mathrm{pH}$ measurements were made before and after feeding using a Beckman $Ф 390 \mathrm{pH}$ meter. More detailed $\mathrm{pH}$ measurements (usually on two hours basis) were made at selected feeding cycles (between two consecutive feedings). The concentrations of $\mathrm{NH}_{4}-\mathrm{N}, \mathrm{NO}-\mathrm{N}$ and $\mathrm{NO}_{2}-\mathrm{N}$ in the five columns were measured at selected feeding cycles. $\mathrm{NH}_{4}^{+}, \mathrm{NO}_{3}^{-}$, and $\mathrm{NO}_{2}^{-}$ analyses were performed with Dr. Lange mobile photometer (Lasa 100) by using Dr. Lange analysis cuvettes LCK 335 (ammonium), LCK 340 (nitrate) and LCK 342 (nitrite). COD (s) measurements were made by using the closed reflux colorimetric method with Hach DR2000 photometer. For the analyses of $\mathrm{NH}_{4}^{+}, \mathrm{NO}_{3}^{-}, \mathrm{NO}_{2}^{-}$and $\mathrm{COD}(\mathrm{s}), 10 \mathrm{ml}$ samples were taken from the each column and centrifuged at $9000 \mathrm{rpm}$ for 10 minutes and then the supernatants were filtered through $0.45 \mu \mathrm{m}$ syringe filters and finally diluted to required ranges $(10,20$ or 50 times) using deionized water. The levels of dissolved oxygen in the reactors were measured using WTW Oxi 340-A oxygen meter in order to confirm that a sufficient aeration efficiency was maintained in the reactor assay. Sludge sedimentation rates of the different reactor columns were estimated at the start and at the end of the 32 days long steady feeding phase. Standard methods were used to determine the total suspended solids (TSS) and volatile solids (VS) contents of the feed digestate [7].

\section{RESULTS AND DISCUSSION}

\subsection{System monitoring via $\mathrm{pH}$ measurements}

The variation of $\mathrm{pH}$ during each consecutive feeding interval ( 1 day) was monitored as an easy and appropriate way of following the nitrification dynamics in the reactors. The $\mathrm{pH}$ drop follows nitrification as nitrification consumes $7.07 \mathrm{~g}$ alkalinity (as $\mathrm{CaCO}_{3}$ equivalent) per gram of $\mathrm{NH}_{4}-\mathrm{N}$ converted [8]. According to Figure 2a, it is clear that $\mathrm{pH}$ respond consistently to feeding cycles. A closer look at the $\mathrm{pH}$ measurements for all 5 reactors during two consecutive feeding cycles confirm the consistent $\mathrm{pH}$ response and show that differences between the reactors can be detected (Figure $2 b$ ).

Columns fed $30 \mathrm{ml}$ of digestate (columns 3,4 and 5) show a larger $\mathrm{pH}$ drop, compared to the columns fed $20 \mathrm{ml}$ of digestate (columns 1 and 2), but maintain a higher average pH (Figure $2 b$ ), suggesting that ammonia availability is the limiting factor in these tests. The columns fed pre-sedimented digestate ( 1 and 5 ) had less alkalinity compared to the columns fed unsedimented digestate (2,3 and 4), resulting in a steeper $\mathrm{pH}$ drop. This is illustrated by comparing the $\mathrm{pH}$ curves of columns with the same feed volume; 5 with 4 and 1 with 2 (Figure $2 b$ ). The suspended solids present in the digestate evidently contribute additional buffer capacity via dissolution of solids to soluble ions. 


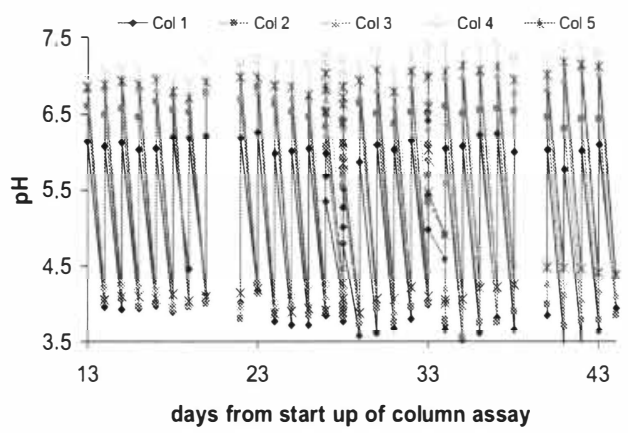

Figure 2a. $\mathrm{pH}$ variation for the duration from day 13 to day 44 (steady feeding phase).

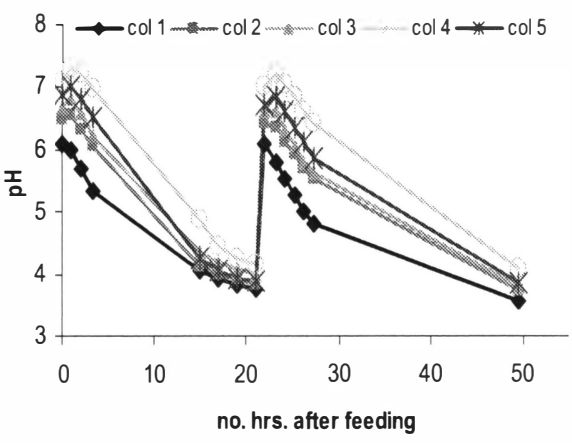

Figure $2 a . p H$ variation for the duration from day 13 to day 44 (steady feeding phase).

At the end of the 32 days long steady feeding duration, the two feeding levels were increased from 20 and $30 \mathrm{~mL} /$ day to 25 and $35 \mathrm{~mL} /$ day. The corresponding $\mathrm{pH}$ measurements suggest that the nitrification rate has dropped significantly after the load increase. For example, before the load increase (on day 43 and day 44) $\mathrm{pH}$ drops observed in a single day time period (between two consecutive feedings) for five columns (col. 1 to col. 5) were 6.1 to 3.9, 6.4 to $3.8,7.0$ to $4.1,7.3$ to 4.4 and 7.1 to 4.4 respectively. But after the load increase (on day 44), it took four days for the $\mathrm{pH}$ in columns 1 and 5 to drop from 7.3 to 4.1 and from 7.3 to 4.5 , respectively (without any feeding in between). This condition was defined as an overload. Meanwhile, for columns 2, 3 and 4, pH value drops were 6.9 to 3.3, 7.2 to 3.9, and 7.5 to 4.5, respectively, and these drops took place during two days time period (without feeding in between). However, during the next two feeding cycles (on day 48 and day 50), all columns behaved in a more similar manner and $\mathrm{pH}$ dropped below 4.5 within two days time period (without feeding in between). But the initial (just after feeding) $\mathrm{pH}$ values started to increase beyond the previously intended 6.0 and 7.0 limits and ascend towards 7.5 for most of the reactors. Thus on day 52 , it was decided to reduce the feed rates back to 20 and $30 \mathrm{~mL} /$ day and to observe the recovery of the reactors to early conditions. This phase continued for another 14 days and the detailed $\mathrm{pH}$ measurements made during a single feeding cycle (days 68 - 69) were illustrated in Figure 3. It is evident that these $\mathrm{pH}$ curves correspond well with the curves shown in Figure $2 b$ except for the behavior of column 3. It is concluded that the reactor column 3 has failed in its activity at this stage. However its almost parallel reactor column 4 had not failed in a similar way. When searching for an explanation it was seen from $\mathrm{pH}$ data (not shown here) that until the day 63 both columns 3 and 4 behaved in a parallel manner. After feeding on day 63 , the initial $\mathrm{pH}$ values were 7.4 in both the columns, but during the next day column 4 dropped to $\mathrm{pH}$ of 4.6 meanwhile column 3 dropped only to 5.6. After this, the column 3 never recovered and consecutive feedings led to higher and higher initial (after feed) $\mathrm{pH}$ values until a complete failure occurred. Figure 4 illustrates the behavior of column 3 during this time period. As a recovery measure, on day 67 column 3 was not fed for one cycle which resulted in positive signs of recovery as seen in Figure 4. After feeding on day 68 , the $\mathrm{pH}$ of column 3 returned to a lower value of 6.7 compared to the value of 7.7 on day 67 . Nevertheless, this series of experiments was terminated on day 69 . 
The exact reason for the sudden loss of nitrification in column 3 on day 63 was not clear but could have caused by the loss of aeration for a certain period. However the complete failure could have been avoided if the feeding on next cycle was stopped. Feed accumulation can lead to increased amounts of free ammonia $(\mathrm{NHę)}$ ) and even at low concentrations like 0.1 $\mathrm{mg} / \mathrm{L}$, free ammonia can inhibit nitrifying organisms [5]. However this is a clear example of the nature ofebioreactor failures commonly found in practice and it emphasizes the importance of detecting the early signs of failures by simple measurement techniques (like $\mathrm{pH}$ ) and the necessity of taking direct corrective measures quickly as possible to avoid complete system failures on course.

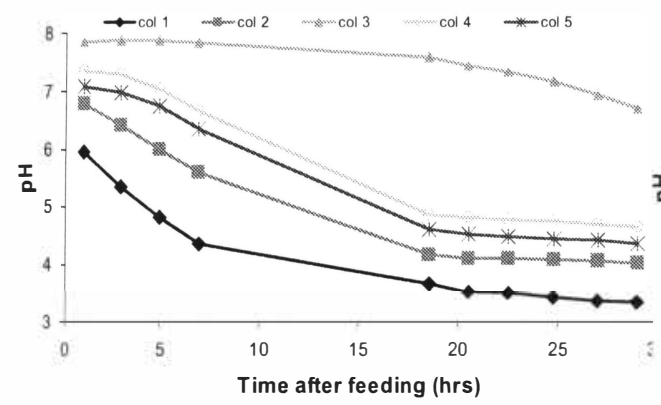

Figure 3. Detailed $\mathrm{pH}$ measurements for a single feeding cycle (days 68-69).

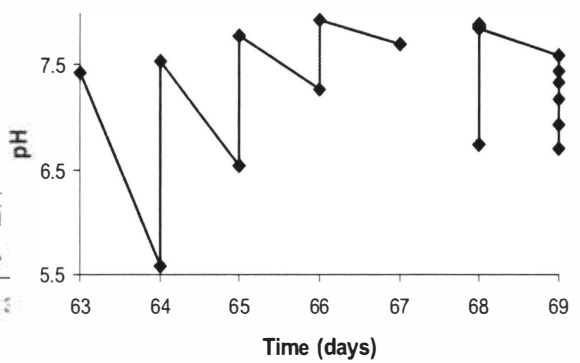

Figure 4. Progressive failure of reactor column 3 (from day 63 to day 69).

\subsection{Nitrification during a single cycle}

Figure $5 a$ and Figure $5 b$ show the variation of $\mathrm{NH}_{4}-\mathrm{N}$ and $\mathrm{NO}_{3}-\mathrm{N}$ concentrations (in mg/L) respectively in reactor columns during a single feeding cycle (days $33-34$ ). Greater than $75 \%$ conversion of ammonical nitrogen to nitrate nitrogen is observed in most of the time. But significant ammonia losses are also observed in some columns $(24 \%$ in column 1 and $27 \%$ in column 5) and can be linked to the assimilation into microbial cells and stripping out as $\mathrm{NH}_{3}$ at the higher $\mathrm{pH}$ conditions prevailing in the early phase of the cycle. Pambrun et al. (200区) [9] observed that ammonia loss due to combined effect of assimilation and stripping could be as high as $10 \mathrm{e}-20 \%$. Instant ammonia stripping was observed also by Yamamoto et al. (2006) [5] while experimenting on nitrification of anaerobically digested swine wastewater. They further reported that nitrification conditions were restored to a greater degree by lowering the $\mathrm{pH}$ from 9.0 to below 7.5 .

As should be expected, the columns fed $30 \mathrm{ml}$ per day (3, 4 and 5) shows higher nitrate concentrations compared to the columns fed $20 \mathrm{ml}$ per day ( 1 and 2), (Figure $5 \mathrm{~b}$ ). The columns fed pre-sedimented digestate had lower nitrate accumulation than the columns fed unsedimented digestate ( 1 and 5). For example, column 5 had significantly lower nitrate content than columns 3 and 4 (which are parallel to each other) fed the same amount of unsedimented digestate. Comparison of columns 1 and 2 further confirms this observation. 


\section{Kalmar ECO-TECH '07}

KALMAR, SWEDEN, November 26-28, 2007

It is plausible that suspended solids (SS) may release extra $\mathrm{NH}_{4}-\mathrm{N}$ during the process leading to higher $\mathrm{NO}_{3}-\mathrm{N}$ levels. This may as well explain the $\mathrm{NH}_{4}-\mathrm{N}$ and $\mathrm{NO}_{3}-\mathrm{N}$ imbalance observed in columns 2 and 4, where a higher amount of $\mathrm{NO}_{3}-\mathrm{N}$ has resulted than the measured $\mathrm{NH}_{4}-\mathrm{N}$ decrease (see Figures $5 a$ and $5 b$ ). This can happen when SS release additional $\mathrm{NH}_{4}-\mathrm{N}$ upon the depletion of $\mathrm{NH}_{4}-\mathrm{N}$ concentration in the solution phase. Note that, only the solution phase concentrations were determined during analysis. It was observed by [10] that large amounts of $\mathrm{NH}_{4}-\mathrm{N}$ can be present in the solid phase of sludge. The mineralization of bound nitrogen in the solids was also confirmed in analyses made during this study. The portion of plant available nitrogen in the digestate increased after nitrification (data not shown).

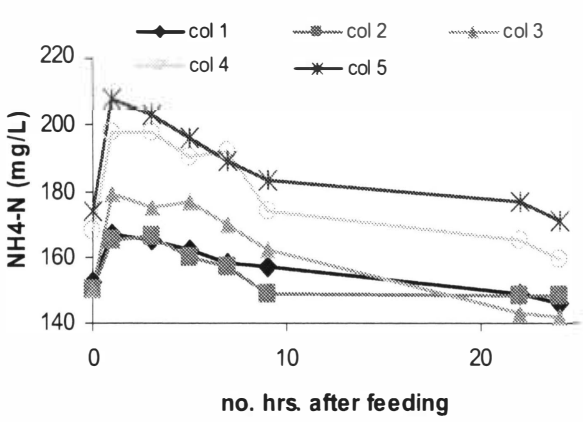

Figure $5 \mathrm{a}$. $\mathrm{NH}_{4}-\mathrm{N}$ reduction during a single feeding cycle (days 33 - 34).

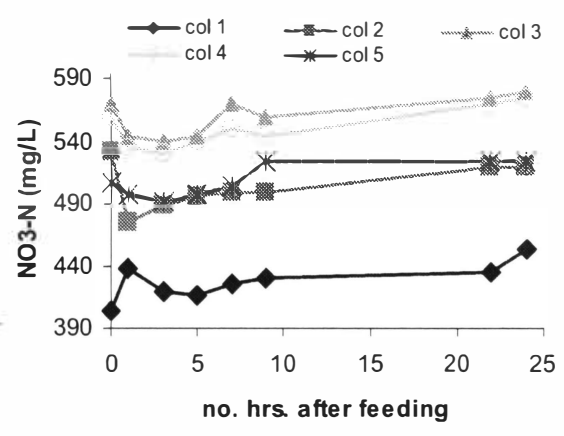

Figure $5 b . \mathrm{NO}_{3}-\mathrm{N}$ increase during the same feeding cycle (days 33 - 34).

The amount of nitrogen present as nitrite $\left(\mathrm{NO}_{2}-\mathrm{N}\right)$ was measured and found to be low (below $10 \mathrm{mg} / \mathrm{L}$ ). Since nitrite is an intermediate product, it will be consumed and converted rapidly to nitrate $\left(\mathrm{NO}_{3}{ }^{-}\right)$unless special provisions are made to inundate the nitrite oxidizing organisms via low sludge retention time, low dissolved oxygen or high level of free $\mathrm{NH}_{3}$ inhibition. Nitrite oxidizing organisms have a lower yield and lower oxygen uptake compared to the ammonia oxidizing organisms [2]. Conditions to favor nitrite oxidation were promoted here and dissolved oxygen levels in the reactor columns were measured to be high all the time with values exceeding $8.0 \mathrm{mg} / \mathrm{L}$ (at the temperature of $25^{\circ} \mathrm{C}$ ).

COD (soluble) measurements were also made as an additional indicator of the biological activity. In the majority of the reactors, a temporary increase of soluble COD during the early phase of the feeding cycles was observed. It is possible that this can be attributed to the degradation of particulate COD [6]. However, the lack of homogeneity of reactor fluid at the beginning of the feeding may also have caused this behavior. The overall reduction of soluble COD during the cycle indicated that there was a reasonable level of heterotrophic bacterial activity in addition to the autotrophes. This could have helped to breakdown the recalcitrant compounds surviving the anaerobic digestion. High COD (soluble) value of $3260 \mathrm{mg} / \mathrm{L}$ observed in the undiluted digestate (Table l) confirms the presence of such anaerobic defiant compounds. The differences in COD variation for the five columns were not especially perceptible but apparently in accordance with the feeding volumes. 
Columns 3, 4 and 5 which were fed with $30 \mathrm{~mL}$ of digestate per day indicated higher COD values compared to the columns ( 1 and 2 ) fed with $20 \mathrm{~mL}$ per day.

\subsection{Sedimentation quality}

Sedimentation effectiveness of the sludge in diffierent reactor columns was examined by carrying out simple sedimentation tests prior to the start up and also at the end of the 32 days long steady feeding phase experiment (sedimentation tests were carried out on day 11 and day 44 (see Figures $6 a$ and $6 b$ ). Generally, it is clear that a significant improvement of sedimentation quality of the reactor mixed liquor has occurred with the establishment of an efficient nitrification process. The anaerobic digestate had very poor sedimentation qualities. Even after centrifugation at $9000 \mathrm{rpm}$ for 15 minutes, a clear liquid phase was not obtained (the same dark color as the original digestate remained). Filtration of the supernatant (resulting from centrifugation) through a $0.45 \mu \mathrm{m}$ filter, however, produced a filtrate with a yellowish color. This indicates that the digestate contains a significant amount of colloidal solids which cannot be easily settled. However the nitrified mixed liquor from reactor columns produced a clear phase with the same yellowish color as obtained by filtering the original digestate through $0.45 \mu \mathrm{m}$ filters, just by allowing it to settle for 15 minutes. This improvement of effluent quality by accelerated sedimentation (hence enhanced clarity) after nitrification can play a major role in producing a commercially acceptable liquid fertilizer.

The effiect of pre-sedimentation of the digestate seems to be marginal on the final sedimentation characteristics of the effluent. The sedimentation rates of the all five columns at the end of the 32 days duration are pretty similar in practical terms (Figure $6 b$ ). However it does show a bit slower sedimentation rate in the columns 1 and 2 at the beginning of the sedimentation test. This difference may be related to the hydraulic retention time (HRT) of the reactors. Columns 1 and 2 were operated with a 50 days HRT $(20 \mathrm{~mL} /$ day feed rate $)$ while columns 3, 4 and 5 were operated with a HRT of 33 days $(30 \mathrm{ml} /$ day feeding). Thus, after 32 days experimentation, columns 1 and 2 still virtually carries $36 \%$ of its initial mixed liquor (inoculated) while the other three columns have almost rejuvenated their reactor contents with feed digestate. Note that a part of the inoculum for this study was taken from a waste treatment facility in an oil refinery and hence oily substances present with sludge (even in minor quantities) may reduce the sedimentation rate. The slower sedimentation observed at the beginning (Figure 6a) may also have caused partly due to this fact.

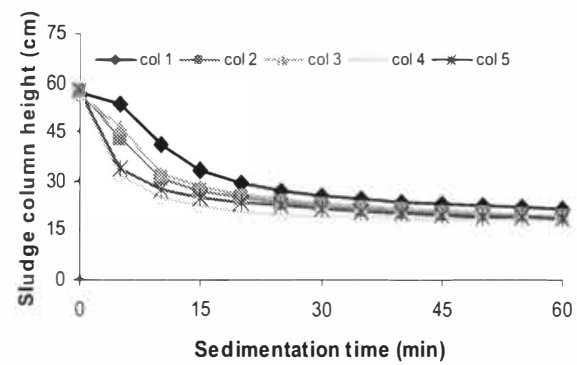

Figure 6a. Sedimentation tests carried out on day 11 .

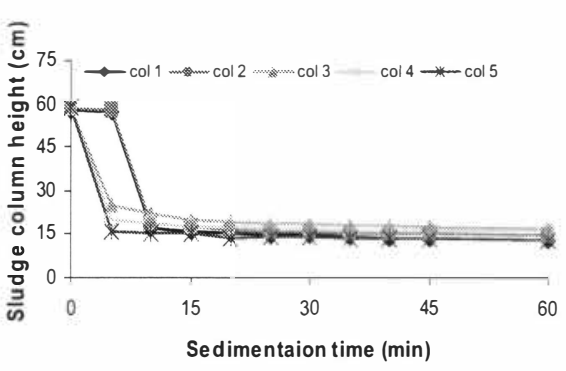

Figure $6 b$. Sedimentation tests carried out on day 44. 


\section{CONCLUSIONS}

Nitrification of digestates from anaerobic digesters operating on source separated municipal organic wastes containing high amounts of ammonical nitrogen $(\sim 1700 \mathrm{mg} / \mathrm{L})$ can be accomplished successfully without addition of extra buffer capacitye Nitrification of such digestates would lead to a stable, aesthetically improved (free from particulates and strong odors) liquid $\mathrm{N}$-fertilizere The process should be operated at $\mathrm{pH}$ levels below neutral to avoid ammonia stripping, a condition that can be obtained by proper feeding schemese However the extent of nitrification can be limited by the alkalinity and also by the ammonium content in the feede

It is advantageous to conduct the nitrification without pretreatment for removing the particulate fraction of the digestate, as solids can contribute additional $\mathrm{NH}_{\mathbf{\varphi}} \mathrm{N}$ and buffer capacitye Significantly improved sedimentation characteristics are observed with the nitrified effluent compared to the anaerobic digestatee

However it is believed that further observations must be done in pilot scale before planning a commercial scale production scheme based on this concept. Moreover, the real field compatibility of the intended fertilizer product must be confiemed by conducting a series of plant growth testse

\section{ACKNOWLEDGEMENTS}

The authors wish to express their gratitude to the staff members of Telemark University College and Bio-Tek AS, for their support contributed at different stages of this studye A special thank goes to Mrse Hildegunn H. Haugen, Laboratory Engineer at Telemark University College for her generous assistance provided during experimentinge Fellow researcher Carlos Røed shall also be mentioned here for valuable comments offered at several occasionse

\section{REFERENCES}

[1] Fokes, J. (2007)e Nitrogen balance for the urban food metabolism ofeToranto, Canadae Resources, Conserv Recycl. Article in Press. Doiel 0.1016/j.resconrec.2007.02.003.

[2] Bernet, N., Delgenes, N., Akunna, J. C., Delgenes, J. P., Moletta, R. (2000). Combined anaerobic aerobic SBR for the treatment of piggery wastewatere Water Research, Vole 34, Noe2, pp. 611-619.

[3] The Council of the European communities. (1991). Council Directive of 21 May 1991, concerning urban waste water treatment $(91 / 271 /$ EEC).

[4] Crab, R., Avnimelech Y., Defoirdt, T., Bossier P., Verstraete W. (2007). Nitrogen removal techniques in aquaculture for a sustainable production. (Review Article)e Aquaculture 270 (2007), pp. 1-14e

[5] Yam amoto, T., Takaki, K., Koyama, T., Furukawa, K. (2006). Novel partial nitritation treatment for anaerobec digestion liquor of swene wastewater useng swem bed technology. J. Bioscience and Bioengineering, vol. 102, Noe6, ppe497-503.

[6] Luostarinen, S., Luste, S., Valentin, L., Rintala, J. (2006). Nitrogen removal from onsite treated anaerobic effluents using inteemittently aerated moving bed biofilm reactors at low temperatures. Water Research 40 (2006), ppe 1607-1615e

[7] APHA. (1989). Standard methods for examination of water and wastewater, 17 the ede Washington, DCe APHA-AWWA-WPCF, 1989. 
[8] Metcalf and Eddy. (2003). Wastewater Engineering, Treatment and Reuse. Tata McGrow-Hill publishing company. $4^{\text {th }}$ Edition, 2003.

[9] Pambrun, V., Paul, E., Sperandio, M. (2007). Control and modeling of partial nitrification of effluents with high ammonia concentrations in sequencing batch reactor. Chem. Eng. and Processing, Article in Press.

[10] Meknassi, Y. F., Tyagi, R. D., Narasiah, K. S. (2000). Simultaneous sewage sludge digestion and metal leaching: effect of aeration. Process Biochemistry 36 (2000), pp. 263-273. 